\title{
Correction to: Balanced renewable energy scenarios: a method for making spatial decisions despite insufficient data, illustrated by a case study of the Vorderland-Feldkirch Region, Vorarlberg, Austria
}

Pia Nabielek, Hartmut Dumke* and Kurt Weninger

\section{Correction}

In the publication of this article [1], there is an error in the Figures 4, 5 and 6 which are missing the map design and data source of the copyright owners.

Should instead read:

Figure 4:

Map design: Kurt Weninger.

Data source: basemap.at, $\odot$ OpenStreetMap \& Contrib.

Figure 5:

Map design: Kurt Weninger.

Data source: basemap.at, $\odot$ OpenStreetMap \& Contrib.,

European Environment Agency.

Figure 6:

Map design: Kurt Weninger.

Data source: basemap.at, (O) OpenStreetMap \& Contrib.,

(c) Land Vorarlberg.

This has now been included in this erratum.

Published online: 26 February 2018

\section{Reference}

1. Nabielek P, Dumke H, Weninger K (2018) Balanced renewable energy

scenarios: a method for making spatial decisions despite insufficient data, illustrated by a case study of the Vorderland-Feldkirch Region, Vorarlberg, Austria. Energ Sustain Soc 8:5 https://doi.org/10.1186/s13705-017-0144-x

\footnotetext{
* Correspondence: hartmut.dumke@tuwien.ac.at

Department of Spatial Planning, Vienna University of Technology, Vienna,

Austria
} 